\title{
RECURSOS ESTRATÉGICOS PARA A PRODUÇÃO ENXUTA: UM ESTUDO DE CASO NO SETOR DE MANUFATURA ELETRÔNICA
}

\section{STRATEGIC RESOURCES FOR LEAN PRODUCTION: A CASE STUDY IN THE ELECTRONIC MANUFACTURING INDUSTRY}

\author{
Nayara Cardoso de Medeiros* E-mail: naycardoso@hotmail.com \\ Luciano Costa Santos* E-mail: luciano@ct.ufpb.br \\ Cláudia Fabiana Gohr* E-mail: claudiagohr@ct.ufpb.br \\ Felipe de Souza Tomé* E-mail: felipestome@hotmail.com \\ *Universidade Federal da Paraíba (UFPB), João Pessoa, PB
}

\begin{abstract}
Resumo: Muitas empresas que tentam implementar a produção enxuta falham ao negligenciar o aspecto estratégico envolvido na mudança organizacional que demanda um novo modelo de gestão. Analisando pela ótica da visão baseada em recursos, é necessário identificar os recursos estratégicos que dão suporte para a implementação, de forma a proteger, explorar e desenvolver os recursos que que viabilizam a produção enxuta. Adotando essa perspectiva, este artigo teve o objetivo de analisar a implementação da produção enxuta em uma empresa de manufatura eletrônica, identificando os recursos mais importantes para o processo. A abordagem metodológica utilizada foi o estudo de caso, no qual a entrevista semiestruturada constituiu o principal instrumento de coleta de dados. Foram identificadas 11 práticas de produção enxuta implementadas e 13 recursos de suporte à implementação. De um modo geral, os resultados demonstraram a importância dos recursos intangíveis para a implementação e a manutenção da produção enxuta na empresa, em especial: cultura organizacional, valores e funcionários. De um modo específico, foi possível identificar quais recursos são mais representativos para cada prática enxuta, o que ajuda a melhorar a decisão sobre quais recursos investir de acordo com as prioridades de implementação.
\end{abstract}

Palavras-chave: Produção Enxuta. Visão Baseada em Recursos. Implementação.

Abstract: Many companies that try to implement lean production fail to neglect the strategic aspect involved in organizational change that requires a new management model. From the perspective of resource-based view, it is necessary to identify the strategic resources that support the implementation, in order to protect, explore and develop the resources that that enable lean production. Adopting this perspective, this article aimed to analyze the implementation of lean manufacturing in an electronic manufacturing plant, identifying the most important resources for the process. The methodological approach used was the case study, in which the semi-structured interview was the main data collection instrument. It was identified 11 lean production practices implemented and 13 resources to support the implementation. In general, the results showed the importance of intangible resources for the implementation and maintenance of lean production at the company, in particular: organizational culture, values and employees. Specifically, it was possible to identify which resources are most representative for each lean practice, which helps to improve the decision about what resources to invest in accordance with the implementation priorities.

Keywords: Lean Production. Resource Based View. Implementation. 


\section{INTRODUÇÃO}

Desde o seu surgimento, a produção enxuta (PE) tem despertado o interesse de pesquisadores e empresários. No entanto, enquanto muitas empresas que adotaram a produção enxuta tiveram sucesso, outras falharam no processo de implementação e não obtiveram os resultados esperados (TAYLOR; TAYLOR; MCSWEENEY, 2013). Um dos fatores apontados por Bhasin e Burcher (2006) como causa para 0 insucesso na implementação é a falta de direcionamento e planejamento, negligenciando o fato de que a produção enxuta é uma jornada de longo prazo. Nesse sentido, Veiga (2009) considera que a falta de sustentabilidade em longo prazo da produção enxuta pode ser explicada pela ausência de uma perspectiva estratégica para sua implementação.

Ao incorporar a perspectiva estratégica, a visão baseada em recursos (VBR) representa uma importante teoria que pode ser considerada no processo de implementação da produção enxuta quando se visa o longo prazo e a sua sustentabilidade. De acordo com Kraaijenbrink, Spender e Groen (2010), a VBR considera que os recursos internos de uma empresa são tão importantes quanto os fatores externos no processo de implementação da $\mathrm{PE}$, pois esses recursos podem criar barreiras efetivas para imitação da concorrência.

Analisando a literatura da área, é possível verificar que algumas pesquisas foram desenvolvidas com o intuito de relacionar os recursos da empresa com as práticas de produção enxuta. Lewis (2000), por exemplo, foi pioneiro ao argumentar em sua pesquisa que a PE pode alavancar a vantagem competitiva, pois o processo de implementação da PE pode criar recursos estratégicos que permitem o desenvolvimento de vantagens competitivas sustentáveis. De uma forma geral, as pesquisas atuais apontam que a produção enxuta só se torna sustentável quando a empresa mantém seu investimento nos recursos estratégicos que dão suporte ao sistema.

Considerando o exposto, esta pesquisa tem como objetivo analisar a implementação da Produção Enxuta pela ótica da visão baseada em recursos, reconhecendo que esse processo depende do desenvolvimento de recursos de suporte. Para tanto, foi conduzido um estudo de caso em uma empresa de manufatura eletrônica que passou por um processo recente de implementação da produção enxuta. Além de verificar a trajetória de implementação da PE, o estudo procurou verificar os recursos mais importantes para o processo de implementação e manutenção da produção enxuta. Por meio do estudo de caso, foi possível identificar fatores críticos para a implementação da produção enxuta, considerando os diferentes recursos necessários para esse processo.

Após esta introdução, o trabalho encontra-se estruturado da seguinte forma: (i) revisão da literatura sobre os principais temas que deram sustentação para o estudo empírico; (ii) procedimentos metodológicos, em que se discute detalhadamente como a pesquisa foi desenvolvida; (iii) descrição e análise dos resultados, demostrando a interação dos recursos com as práticas de produção 
enxuta na empresa estudada e, por fim, (iv) discussões adicionais e conclusão do trabalho.

\section{A PRODUÇÃO ENXUTA E A VISÃO BASEADA EM RECURSOS}

A produção enxuta (PE) surgiu como uma generalização do Sistema Toyota de Produção (STP), que tinha como objetivo prioritário a eliminação de desperdícios e permitia que a empresa (Toyota Motor Company), ainda pequena no surgimento do STP, fosse competitiva no cenário mundial da indústria automobilística (WOMACK; JONES, 2003). A produção enxuta hoje tem uma conotação mais ampla e é composta de um conjunto de práticas complementares entre si que dão suporte aos seus princípios.

A PE envolve princípios que ajudam a entender melhor seus fundamentos e perspectivas (WOMACK; JONES, 2003) e que norteiam a empresa rumo aos seus objetivos de desempenho. Alguns dos princípios básicos são, segundo Womack e Jones (2003):

a) Especificar valor: determinar precisamente o valor agregado por produto específico.

b) Identificar o fluxo de valor: mapear a cadeia de valor para cada produto.

c) Garantir o fluxo: fazer o valor fluir sem interrupções.

d) Trabalhar com produção puxada: deixar que o cliente puxe valor do produto.

e) Buscar a perfeição: princípio da melhoria contínua.

Saurin e Ferreira (2008) explicam que as práticas da produção enxuta viabilizam a implementação de princípios da $\mathrm{PE}$ e que, devido a uma constante evolução desse sistema e de sua rápida disseminação, não existe ainda um consenso na literatura sobre suas práticas e seus princípios fundamentais. Entretanto, para este trabalho foram selecionadas 12 práticas identificadas na literatura que serviram de base para a pesquisa. Essas práticas estão apresentadas no Quadro 1 com seus respectivos conceitos.

Em geral, o sucesso na adoção de qualquer prática de produção enxuta depende das características organizacionais e variáveis contextuais (TORTORELLA et al., 2014), sendo que nem todas as organizações podem ou devem aplicar o mesmo conjunto de práticas. Além disso, a PE deve ser implementada em alinhamento com a estratégia de operações da empresa (VEIGA, 2009).

Diante da necessidade de alinhar a estratégia com a implementação da PE, a visão baseada em recursos (VBR) (BARNEY; HESTERLY, 2007) começou a ser considerada uma teoria relevante para a compreensão dos fatores que garantem o sucesso na implementação da produção enxuta a longo prazo (JAYAMAHA et al., 2014).

Considerando que a VBR tem seu foco nos recursos e capacidades de uma empresa, Barney e Hesterly (2007) definem os recursos como ativos tangíveis e intangíveis que a empresa controla e que podem ser usados para criar e 
implementar estratégias. Já as capacidades, segundo os mesmos autores, "é um subconjunto de recursos que permite à empresa um melhor aproveitamento dos outros recursos" (BARNEY; HESTERLY, 2007, p. 64). Fleury e Fleury (2003) afirmam que toda empresa possui um portfólio de recursos: físicos, financeiros, intangíveis (marca, imagem, etc.), organizacionais (cultura organizacional, sistemas administrativos, etc.) e humanos. É a partir desse portfólio que a empresa pode criar vantagens ao alinhar recursos com prioridades competitivas (GOHR; SILVA, 2015).

Quadro 1 - Práticas de Produção Enxuta

\begin{tabular}{|c|c|}
\hline PRÁTICAS & CONCEITO \\
\hline Equipes multifuncionais & $\begin{array}{l}\text { As equipes multifuncionais consistem em grupos de trabalhadores } \\
\text { que realizam várias tarefas diferentes, conferindo flexibilidade ao } \\
\text { sistema de produção (MONDEN, 2015). }\end{array}$ \\
\hline $\begin{array}{l}\text { Gestão da qualidade no } \\
\text { processo }\end{array}$ & $\begin{array}{l}\text { Prevê a eliminação ou a simplificação de processos que não } \\
\text { adicionam valor ao produto e também a atuação do controle de } \\
\text { qualidade de forma preventiva, eliminando erros no processo (LIKER, } \\
\text { 2005). }\end{array}$ \\
\hline Gerenciamento visual & $\begin{array}{l}\text { O gerenciamento visual consiste em expor informações visuais sobre } \\
\text { problemas e indicadores do sistema produtivo (MONDEN, 2015) }\end{array}$ \\
\hline $\begin{array}{l}\text { Produção puxada, Just in } \\
\text { time (JIT) }\end{array}$ & $\begin{array}{l}\text { Fornecer itens necessários, na quantidade necessária, no momento e } \\
\text { no local correto para eliminar estoques e perdas e obter um fluxo } \\
\text { contínuo de produção (SHINGO, 1996; OHNO, 1997). }\end{array}$ \\
\hline Kanban & $\begin{array}{l}\text { O kanban é uma forma para se atingir o just in time por meio de } \\
\text { cartões que contém informações de coleta, transferência e de } \\
\text { produção que são enviados de um processo para o seu antecessor } \\
\text { (OHNO, 1997). }\end{array}$ \\
\hline Células de manufatura & $\begin{array}{l}\text { As células de manufatura são disposições de layout de um sistema } \\
\text { produtivo em que há um agrupamento das máquinas de forma a } \\
\text { reduzir a movimentação dos funcionários, diminuir o transporte de } \\
\text { materiais, diminuir o estoque de materiais, além de manter uma } \\
\text { relação mais próxima entre as equipes de trabalho (MONDEN, 2015). }\end{array}$ \\
\hline $\begin{array}{l}\text { Manutenção produtiva total } \\
\text { (TPM) }\end{array}$ & $\begin{array}{l}\text { Abordagem estruturada de manutenção que reúne um conjunto de } \\
\text { técnicas para evitar interrupções inesperadas no fluxo de produção } \\
\text { por meio de manutenção autônoma e planejada (LIKER, 2005). }\end{array}$ \\
\hline $\begin{array}{l}\text { Mapeamento do fluxo de } \\
\text { valor }\end{array}$ & $\begin{array}{l}\text { Mapear o fluxo de valor é descrever o caminho de todo o processo de } \\
\text { transformação de material e informação de forma a identificar as } \\
\text { atividades que não agregam valor (LIKER, 2005). }\end{array}$ \\
\hline Melhoria contínua (Kaizen) & $\begin{array}{l}\text { A melhoria contínua tem por filosofia não aceitar o status quo de uma } \\
\text { organização e sempre realizar as mudanças de modo incremental e } \\
\text { rotineiro (MONDEN, 2015). }\end{array}$ \\
\hline $\begin{array}{l}\text { Nivelamento da produção } \\
\text { (Heijunka) }\end{array}$ & $\begin{array}{l}\text { Nivelamento da produção em volume e em combinação ( mix), ou } \\
\text { seja, toma o volume total de pedidos em um período e o nivela para } \\
\text { que a mesma quantidade e combinação sejam produzidas a cada dia } \\
\text { (LIKER, 2005). }\end{array}$ \\
\hline Operações padronizadas & $\begin{array}{l}\text { As operações padronizadas buscam ajudar a diminuir as ineficiências } \\
\text { do processo, por meio do estabelecimento de padrões de tempos e } \\
\text { métodos (MONDEN, 2015). }\end{array}$ \\
\hline $\begin{array}{l}\text { Troca rápida de } \\
\text { ferramentas }\end{array}$ & $\begin{array}{l}\text { Tem como objetivo reduzir o tempo de setup por meio da } \\
\text { simplificação e melhoria das atividades de preparação (SHINGO, } \\
\text { 1996). }\end{array}$ \\
\hline
\end{tabular}

Fonte: Elaborado pelos autores 
Barney e Hesterly (2007) classificam os recursos em: recursos financeiros, recursos físicos, recursos individuais (geralmente recursos humanos) e recursos organizacionais (estrutura formal da empresa, seus sistemas formais e informais de planejamento, controle e coordenação, cultura e reputação, relações informais, etc.).

Existem na literatura algumas pesquisas que procuraram relacionar os recursos e a importância destes para a implementação da produção enxuta. Por exemplo, Lewis (2000) destacou que o valor de criar novos processos vai além das fronteiras da empresa, envolvendo clientes atuais e potenciais, tornando a empresa melhor ou diferente. $\mathrm{O}$ autor argumentou que os recursos (qualificação do pessoal, informações de mercado, dados tecnológicos, etc.) criam valor quando resultam em processos intrínsecos à organização. Por sua vez, esses processos permitem que a organização possa aprender e assim criar novos ou reforçar recursos já existentes, possibilitando assim obter a sustentabilidade da vantagem competitiva por meio da produção enxuta (LEWIS, 2000).

Corroborando com o trabalho de Lewis (2000), Forrester et al. (2010) utilizaram a VBR como teoria de análise para identificar que a adoção da produção enxuta tinha um papel significativo na participação de mercado e na criação de valor de empresas brasileiras do setor de máquinas agrícolas. Khanchanapong et al. (2014) também usaram a VBR como lente teórica para constatar o impacto positivo do relacionamento entre práticas enxutas e tecnologias de manufatura (ambos tratados como recursos organizacionais) nas dimensões do desempenho operacional.

Em uma outra pesquisa, Parry, Mills e Turner (2010) desenvolveram uma metodologia para a implementação da PE que se propunha a reduzir o risco de se danificar os principais recursos e habilidades de uma empresa. $O$ método aplicado era constituído por quatro ferramentas: análise de mercado, fluxo visível de valor, análise de valor para o cliente e modelagem financeira. Os autores concluíram que a aplicação conjunta dessas ferramentas com as práticas de produção enxuta estabelecidas pela empresa garantem um menor impacto nos recursos-chave e nas capacidades organizacionais durante o processo de implementação da produção enxuta.

Por sua vez, Gibbons et al. (2012) defenderam em seu trabalho que é preciso compreender como os recursos são distribuídos na empresa e como podem ser melhor alinhados para maximizar a contribuição destes no processo de agregação de valor. Dessa forma, os autores desenvolveram uma matriz que apresentava o estado atual dos recursos de produção enxuta e a partir dessa matriz eles conseguiram visualizar como os recursos estavam alinhados às necessidades funcionais. A partir dessa informação eles elaboraram outra matriz que representava o "estado futuro", de forma a verificar quais atividades precisavam ser removidas, pois não agregavam valor aos recursos empregados no processo de produção enxuta.

Além de conhecer os recursos associados à produção enxuta, é necessário entender os fatores que tornam um recurso importante. Barney e Hesterly (2007) 
consideram que um recurso é importante quando ele consegue preencher quatro requisitos básicos: valor, raridade, inimitabilidade e organização, isto é, a capacidade da empresa de coordenar políticas e processos para tirar proveito desse recurso. De maneira análoga, Mills et al. (2002) propõem três critérios que formam a base para a avaliação de um recurso: valor, sustentabilidade e versatilidade. Em outras palavras, para ser considerado importante, um recurso deve ser valioso para a organização e seus clientes, esse valor deve se manter ao longo do tempo e ter a capacidade de ser transferido para outros processos e unidades da organização.

Nesse sentido, é possível afirmar que é importante identificar e avaliar os recursos da empresa que dão suporte à produção enxuta. Isso permite, por um lado, implementar práticas da produção enxuta adaptando essas práticas aos recursos disponíveis e, por outro, direcionar a estratégia para o desenvolvimento dos recursos atuais e novos que podem apoiar a implementação.

\section{PROCEDIMENTOS METODOLÓGICOS}

A pesquisa foi desenvolvida em duas fases, conforme apresenta o Quadro 2.

Quadro 2 - Procedimentos da pesquisa

\begin{tabular}{|c|c|c|}
\hline $\begin{array}{l}1^{\circ} \text { Etapa: } \\
\text { Revisão de literatura }\end{array}$ & O quê? & Como? \\
\hline 1.1 Produção enxuta & $\begin{array}{l}\text { Identificar conceitos e principais } \\
\text { práticas da PE na literatura. }\end{array}$ & \multirow[b]{2}{*}{$\begin{array}{l}\text { Levantamento } \\
\text { bibliográfico. }\end{array}$} \\
\hline 1.2 Visão baseada em recursos & $\begin{array}{l}\text { Revisar conceitos sobre a visão } \\
\text { baseada em recursos e as } \\
\text { pesquisas que relacionam a VBR } \\
\text { com a PE. }\end{array}$ & \\
\hline $\begin{array}{l}2^{\circ} \text { Etapa: } \\
\text { Estudo de caso }\end{array}$ & O quê? & Como? \\
\hline $\begin{array}{l}\text { 2.1 Práticas da PE } \\
\text { implementadas }\end{array}$ & $\begin{array}{l}\text { Identificar quais as práticas de PE } \\
\text { que foram implementadas na } \\
\text { empresa. }\end{array}$ & \multirow{2}{*}{$\begin{array}{l}\text { Entrevistas } \\
\text { semiestruturadas. }\end{array}$} \\
\hline 2.2 Processo de implementação & $\begin{array}{l}\text { Analisar como as práticas de PE } \\
\text { foram implementadas na } \\
\text { empresa. }\end{array}$ & \\
\hline $\begin{array}{l}2.3 \text { Identificação e avaliação de } \\
\text { recursos }\end{array}$ & $\begin{array}{l}\text { Identificar e avaliar a importância } \\
\text { dos recursos que foram } \\
\text { necessários para a } \\
\text { implementação da PE. }\end{array}$ & $\begin{array}{l}\text { - Entrevistas } \\
\text { semiestruturadas. } \\
\text { - Construção da matriz de } \\
\text { relacionamentos (recursos } \\
\text { x práticas). } \\
\text { - Avaliação dos recursos. }\end{array}$ \\
\hline
\end{tabular}

Fonte: Elaborado pelos autores

A revisão de literatura procurou situar este trabalho em relação às demais publicações na área, especialmente em periódicos internacionais. Foi constatado que a literatura que relaciona a VBR com a PE ainda é escassa, porém aponta para 
a importância de se considerar o aproveitamento e o desenvolvimento de recursos para a implementação bem sucedida da produção enxuta.

A pesquisa de campo foi conduzida por meio de um estudo de caso, que foi desenvolvido em uma empresa do setor de manufatura eletrônica e que tem passado por um processo de implementação da produção enxuta. A escolha da empresa se deu em função da existência de alguns requisitos básicos necessários para o desenvolvimento da pesquisa, tais como estar em um estágio já avançado de implementação da produção enxuta e ter acessibilidade para a realização da coleta de dados.

Após a identificação das práticas de PE adotadas e do detalhamento da experiência de implementação, foi possível identificar os recursos de maior relevância para a produção enxuta na empresa. Para essa análise, foi construída uma matriz de relacionamentos para confrontar os dados sobre as práticas da produção enxuta e os recursos necessários para sua implementação. Essa matriz, cujo formato está representado na Figura 1, foi baseada no trabalho de Silva (2014), porém adotando uma escala diferente para verificar os recursos mais importantes para a implementação das práticas de PE:

1 - Recurso não é importante.

2 - Recurso raramente é importante.

3 - Recurso às vezes é importante.

4 - Recurso quase sempre é importante

5 - Recurso sempre é importante.

Para cada cruzamento prática-recurso, foi atribuída uma pontuação de acordo com a escala acima, de forma que é possível compreender a influência de cada recurso em cada prática. A atribuição de pontos foi feita de maneira interpretativa, a partir da coleta de dados.

A partir da identificação dos recursos mais importantes para a implementação das práticas de $\mathrm{PE}$, procurou-se avaliá-los de acordo com o valor, a sustentabilidade e a versatilidade dos mesmos. A avaliação do valor, da sustentabilidade e da versatilidade dos recursos permite que se possam traçar estratégias para a melhoria dos recursos que dão suporte à implantação das práticas enxutas. A elaboração dos instrumentos de avaliação partiu das planilhas propostas inicialmente por Mills et al. (2002) e adaptadas por Santos et al. (2015). Essas planilhas podem ser visualizadas nas Figuras 2, 3 e 4.

As planilhas das Figuras 2, 3 e 4 preveem a atribuição de uma pontuação total para cada um dos critérios (valor, sustentabilidade e versatilidade), com base no somatório das pontuações individuais de cada questão. Considerando que algumas questões podem não ser aplicáveis, a pontuação total se dá pela seguinte expressão:

$$
\text { Pontuação total }=\frac{\text { Total de questões }(5)}{\text { Total de questões válidas }} \times \Sigma \text { pontuação das questões válidas }
$$


Figura 1 - Matriz de relacionamentos (recursos x práticas)

\begin{tabular}{|c|c|c|c|c|c|c|c|c|c|c|c|c|c|}
\hline \multirow[b]{2}{*}{ Práticas } & \multicolumn{13}{|c|}{ Recursos } \\
\hline & 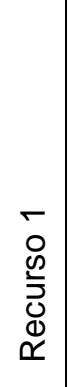 & 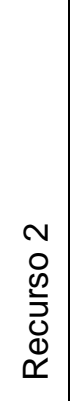 & $\vdots$ & $\vdots$ & $\vdots$ & $\vdots$ & $\vdots$ & $\vdots$ & $\vdots$ & $\vdots$ & $\vdots$ & $\vdots$ & 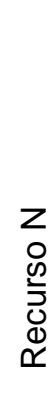 \\
\hline Prática 1 & & & & & & & & & & & & & \\
\hline Prática 2 & & & & & & & & & & & & & \\
\hline$\ldots$ & & & & & & & & & & & & & \\
\hline$\ldots$ & & & & & & & & & & & & & \\
\hline$\ldots$ & & & & & & & & & & & & & \\
\hline$\ldots$ & & & & & & & & & & & & & \\
\hline$\ldots$ & & & & & & & & & & & & & \\
\hline$\ldots$ & & & & & & & & & & & & & \\
\hline$\ldots$ & & & & & & & & & & & & & \\
\hline$\ldots$ & & & & & & & & & & & & & \\
\hline Prática N & & & & & & & & & & & & & \\
\hline Total $(\Sigma)$ & & & & & & & & & & & & & \\
\hline
\end{tabular}

Fonte: Elaborada pelos autores

Figura 2 - Planilha de avaliação do valor do recurso

\begin{tabular}{|c|c|c|c|c|c|}
\hline \multirow{2}{*}{$\begin{array}{l}\text { AVALIAÇÃO DO VALOR DO } \\
\text { RECURSO }\end{array}$} & \multicolumn{5}{|c|}{ PONTUAÇÃO } \\
\hline & 1 & 2 & 3 & 4 & 5 \\
\hline $\begin{array}{l}\text { Qual é o seu efeito sobre a } \\
\text { lucratividade da organização? }\end{array}$ & $\begin{array}{c}\text { Altamente } \\
\text { negativo }\end{array}$ & $\begin{array}{l}\text { Impacto } \\
\text { negativo }\end{array}$ & Impacto nulo & $\begin{array}{l}\text { Impacto } \\
\text { positivo }\end{array}$ & $\begin{array}{l}\text { Altamente } \\
\text { positivo }\end{array}$ \\
\hline $\begin{array}{l}\text { Qual é o seu efeito sobre a } \\
\text { habilidade da organização de } \\
\text { neutralizar ou minimizar as } \\
\text { ameaças do ambiente } \\
\text { competitivo? }\end{array}$ & $\begin{array}{l}\text { Altamente } \\
\text { negativo }\end{array}$ & $\begin{array}{l}\text { Impacto } \\
\text { negativo }\end{array}$ & Impacto nulo & $\begin{array}{l}\text { Impacto } \\
\text { positivo }\end{array}$ & $\begin{array}{l}\text { Altamente } \\
\text { positivo }\end{array}$ \\
\hline $\begin{array}{l}\text { Qual é a sua influência para } \\
\text { ajudar a empresa a explorar as } \\
\text { oportunidades de mercado? }\end{array}$ & $\begin{array}{l}\text { Altamente } \\
\text { negativo }\end{array}$ & $\begin{array}{l}\text { Impacto } \\
\text { negativo }\end{array}$ & Impacto nulo & $\begin{array}{l}\text { Impacto } \\
\text { positivo }\end{array}$ & $\begin{array}{l}\text { Altamente } \\
\text { positivo }\end{array}$ \\
\hline $\begin{array}{l}\text { Quantos concorrentes já } \\
\text { possuem o mesmo recurso? }\end{array}$ & Todos & A maioria & Metade & Alguns & Nenhum \\
\hline $\begin{array}{l}\text { Comparado com a } \\
\text { concorrência, qual o nível de } \\
\text { desempenho desse recurso? }\end{array}$ & $\begin{array}{l}\text { Muito } \\
\text { abaixo da } \\
\text { média do } \\
\text { setor }\end{array}$ & $\begin{array}{l}\text { Abaixo da } \\
\text { média do } \\
\text { setor }\end{array}$ & Na média do setor & $\begin{array}{l}\text { No nível dos } \\
\text { melhores do } \\
\text { setor }\end{array}$ & $\begin{array}{c}\text { Liderança } \\
\text { inquestionável }\end{array}$ \\
\hline
\end{tabular}

\section{PONTUAÇÃO TOTAL}

CLASSIFICAÇÃO

Fonte: Adaptada de Mills et al. (2002) e Santos et al. (2015) 
Figura 3 - Planilha de avaliação da sustentabilidade do recurso

\begin{tabular}{|c|c|c|c|c|c|}
\hline \multirow{2}{*}{$\begin{array}{c}\text { AVALIAÇÃO DA } \\
\text { SUSTENTABILIDADE DO } \\
\text { RECURSO }\end{array}$} & \multicolumn{5}{|c|}{ PONTUAÇÃO } \\
\hline & 1 & 2 & 3 & 4 & 5 \\
\hline $\begin{array}{l}\text { Com que facilidade os } \\
\text { concorrentes podem adquirir } \\
\text { este recurso? }\end{array}$ & Muito facilmente & $\begin{array}{l}\text { Com certa } \\
\text { facilidade }\end{array}$ & $\begin{array}{l}\text { Com certa } \\
\text { dificuldade }\end{array}$ & Dificilmente & $\begin{array}{c}\text { O recurso é } \\
\text { único }\end{array}$ \\
\hline $\begin{array}{l}\text { Quanto tempo demoraria para } \\
\text { um concorrente imitar este } \\
\text { recurso? }\end{array}$ & $<1$ mês & $1-6$ meses & 6-24 meses & $2-5$ anos & $>5$ anos \\
\hline $\begin{array}{l}\text { O recurso foi adquirido ou } \\
\text { desenvolvido por meio de } \\
\text { relacionamentos interpessoais e } \\
\text { confiança? }\end{array}$ & De forma alguma & Dificilmente & Parcialmente & $\begin{array}{l}\text { Em grande } \\
\text { parte }\end{array}$ & Completamente \\
\hline $\begin{array}{l}\text { O recurso foi adquirido ou } \\
\text { desenvolvido por meio do } \\
\text { aprendizado organizacional? }\end{array}$ & De forma alguma & Dificilmente & Parcialmente & $\begin{array}{l}\text { Em grande } \\
\text { parte }\end{array}$ & Completamente \\
\hline $\begin{array}{l}\text { O recurso pode ser substituído } \\
\text { por outro recurso para a } \\
\text { obtenção de um resultado } \\
\text { similar? }\end{array}$ & Completamente & $\begin{array}{l}\text { Em grande } \\
\text { parte }\end{array}$ & Parcialmente & Dificilmente & $\begin{array}{l}\text { De forma } \\
\text { alguma }\end{array}$ \\
\hline
\end{tabular}

\section{PONTUAÇÃO TOTAL}

CLASSIFICAÇÃO

Fonte: Adaptada de Mills et al. (2002) e Santos et al. (2015)

Figura 4 - Planilha de avaliação da versatilidade do recurso

\begin{tabular}{|c|c|c|c|c|c|}
\hline \multirow{2}{*}{$\begin{array}{c}\text { AVALIAÇĀO DA } \\
\text { VERSATILIDADE DO } \\
\text { RECURSO }\end{array}$} & \multicolumn{5}{|c|}{ PONTUAÇĀO } \\
\hline & 1 & 2 & 3 & 4 & 5 \\
\hline $\begin{array}{l}\text { O recurso pode ser } \\
\text { transferido para outros } \\
\text { setores ou unidades na } \\
\text { empresa? }\end{array}$ & Impossível & $\begin{array}{c}\text { Com } \\
\text { dificuldade }\end{array}$ & $\begin{array}{l}\text { Com algum } \\
\text { esforço }\end{array}$ & Facilmente & Muito facilmente \\
\hline $\begin{array}{l}\text { Este recurso depende de } \\
\text { recursos e/ou processos } \\
\text { complementares para ser } \\
\text { transferido? }\end{array}$ & Completamente & $\begin{array}{l}\text { Depende } \\
\text { bastante }\end{array}$ & Parcialmente & Depende pouco & Independente \\
\hline $\begin{array}{l}\text { Este recurso está vinculado } \\
\text { a alguma região } \\
\text { geográfica? }\end{array}$ & Vínculo total & Vínculo forte & Vínculo parcial & Vínculo fraco & Nenhum vínculo \\
\hline $\begin{array}{l}\text { Quanto tempo demoraria } \\
\text { para reproduzir este recurso } \\
\text { em outra parte da } \\
\text { organização? }\end{array}$ & $>5$ anos & $2-5$ anos & 6-24 meses & 1-6 meses & $<1$ mês \\
\hline $\begin{array}{l}\text { A organização tem um } \\
\text { conhecimento explícito dos } \\
\text { fatores necessários para } \\
\text { reproduzir este recurso? }\end{array}$ & $\begin{array}{l}\text { De forma } \\
\text { alguma }\end{array}$ & Muito pouco & Parcialmente & $\begin{array}{l}\text { Em grande } \\
\text { parte }\end{array}$ & Completamente \\
\hline
\end{tabular}

$$
\text { PONTUAÇÃO TOTAL }
$$

\section{CLASSIFICAÇÃO}

Fonte: Adaptada de Mills et al. (2002) e Santos et al. (2015)

De acordo com escala definida, a pontuação total de cada recurso pode variar de 5 a 25 pontos. Para facilitar a classificação do recurso, a amplitude de pontuação foi dividida em cinco níveis de intensidade do recurso: 
- Muito baixo: 5 a 8 pontos;

- Baixo: 9 a 12 pontos;

- Médio: 13 a 17 pontos;

- Alto: 18 a 21 pontos;

- Muito alto: 22 a 25 pontos.

A avaliação final dos recursos mais importantes para a implementação da PE permitiu ter uma noção mais abrangente de necessidade de proteção $e$ desenvolvimento de recursos estratégicos para a produção enxuta. A seção a seguir descreve e analisa os resultados do estudo empírico.

\section{DESCRIÇÃO E ANÁLISE DOS RESULTADOS}

Esta seção relata o caso de uma unidade fabril de uma empresa multinacional americana fornecedora de manufatura eletrônica situada no município de Manaus/AM. A fábrica produz principalmente placas de circuito impresso para setup box, como decodificadores de sinal de televisão digital, e faz a montagem final de câmeras fotográficas.

\subsection{Experiência de implementação das práticas de PE}

A implementação da PE na empresa iniciou no mês de setembro de 2011, com a finalidade de reduzir custos e ampliar a competitividade mercado. O processo foi iniciado com a seleção de uma equipe multidisciplinar envolvendo todos os setores da empresa. A equipe foi qualificada por meio de um treinamento que a empresa denominou de "certificação lean bronze", baseado no programa lean six sigma e adequado para os seus processos. Nesse treinamento os funcionários aprenderam os conceitos e as práticas da PE e no final ficaram responsáveis em implementar, no mínimo, cinco projetos de melhoria.

Para conseguir a certificação lean bronze, os funcionários precisavam cursar 22 módulos de treinamento sobre produção enxuta que abordavam: introdução ao lean six sigma, ferramentas de resolução de problemas, PDCA (plan - planejar, do fazer, check - verificar, act - agir), A3 (ferramenta de solução de problemas em que se resume em uma única folha $A 3$ toda a análise sobre o problema a ser solucionado), DMAIC (Define - Definir, Measure - Medir, Analyze - Analisar, Improve - Melhorar e Control - Controlar), além de outras ferramentas que a PE utiliza para alavancar o processo de melhoria contínua. Ao final, os funcionários em treinamento deveriam fazer uma prova com rendimento igual ou superior a $80 \%$, além da exigência de conduzir cinco projetos de melhoria para se certificar.

A empresa divide os projetos de melhoria em três categorias: kaizen blitz, kaizen process e kaizen system. No kaizen blitz é necessário identificar uma melhoria simples e rápida, baseada no senso comum, e fazer a sua implementação em horas ou até no máximo 3 dias. 0 kaizen process se refere a melhorias de médio 
a grande porte voltadas para um processo específico, enquanto o kaizen system está direcionado para a resolução de problemas mais complexos que geram melhorias para a planta inteira e não apenas para um processo independente.

Após a qualificação da equipe nas práticas de PE, o primeiro evento kaizen que foi realizado na empresa tinha a finalidade de implementar as seguintes práticas: $5 S$ e gerenciamento visual. Essa etapa foi importante para organizar o processo para receber as melhorias. O evento inicial foi de quatro dias, com treinamentos para os dois turnos. Terminada a etapa de treinamento teórico, os colaboradores foram levados para o chão de fábrica para aplicar os novos conhecimentos e dessa forma começaram a implementar pequenas melhorias de 5S nas células de produção.

As adaptações dos padrões de $5 S$ se estenderam ao longo de um mês até o quarto senso do 5S (Utilização, Ordenação, Limpeza e Padronização). O quinto senso, autodisciplina, foi se desenvolvendo ao longo da jornada. A linha na qual foi iniciado o $5 \mathrm{~S}$ foi a de montagem manual e a partir da padronização das mudanças da primeira estação de trabalho foi possível replicar as melhorias para as demais.

Depois do gerenciamento visual e do $5 \mathrm{~S}$, foi desenvolvido o mapeamento do fluxo de valor (MFV) de forma que as necessidades do processo de produção pudessem ser analisadas. Para o MFV, inicialmente foi feito treinamento teórico com duração de cinco dias com os dois turnos da empresa. Depois do treinamento, os colaboradores identificaram o fluxo de materiais e de informação para a elaboração do mapa do estado atual. A partir da configuração do estado atual, foi elaborado o mapa do estado futuro com a identificação da necessidade de implementação de outras práticas, como nivelamento da produção e troca rápida de ferramentas.

Para implementar o nivelamento de produção foi necessário realizar um treinamento que teve duração de três dias. Após este treinamento, o processo de implementação levou um mês e mais 3 meses para verificar a sua eficácia.

Depois do nivelamento da produção a empresa verificou, por meio de um indicador chamado "material handling" (manuseio de material), que cada movimentação que o material faz dentro da empresa - desde a entrada na fábrica, almoxarifado, estante do cliente, inventário central e processo de produção acarretava um custo adicional para a empresa. Diante disso, foi identificada a média da demanda diária, semanal e mensal para, a partir daí, verificar o nível de estoque necessário para ficar na linha de produção, sendo que esse estoque foi denominado na empresa de supermercado. Dessa forma, buscou-se o equilíbrio entre inventário de matéria-prima, inventário em processo e inventário de produto acabado. Paralelamente, foi implementado o kanban passando a utilizar cartões para puxar a produção. A efetivação dessas práticas durou 3 meses.

Depois disso, foi implementada a troca rápida de ferramentas, pois durante o mapeamento de fluxo de valor também foi identificado que a etapa de teste dos circuitos impressos era um gargalo na produção, pois com a troca de modelos, o setup demorava de 3 a 4 horas. Para diminuir esse tempo, a ferramentaria foi levada para mais perto do processo e foi confeccionado um gabarito para o teste. Antes da 
melhoria, para se fazer o teste era necessário desparafusar o JIG, posicionar no eixo correto e parafusar novamente. Com a elaboração desse gabarito não se fez mais necessário retirar o parafuso e nem colocar o eixo no lugar correto, ou seja, pode se colocar a máquina diretamente no teste, eliminando a necessidade de parafusar. Com isso, o setup da máquina de teste caiu para 29 minutos e essa mudança demorou em média 3 meses.

No primeiro ano de implementação foram essas as práticas implementadas no processo de montagem de máquinas fotográficas. No ano seguinte foi utilizada a mesma ordem de implementação para a linha de placas de circuito impresso com a implementação adicional da prática TPM (manutenção produtiva total), devido à identificação quebras de máquinas nessa linha. Porém, foi implementada apenas a manutenção autônoma, com a capacitação dos trabalhadores para terem domínio sobre os equipamentos e serem capazes de realizar melhorias.

Para garantir que as práticas continuassem funcionando, de 3 em 3 meses eram realizadas as chamadas "kaizen blitz", em que eram verificadas as melhorias implementadas e a necessidade de novas melhorias.

A Figura 5 apresenta resumidamente os eventos de implementação da produção enxuta na empresa estudada, em ordem cronológica.

O processo de implementação da PE evidenciou a preocupação constante da empresa em treinar e motivar seus funcionários, envolver todos os níveis gerenciais e prover recursos para as mudanças que foram implementadas.

\subsection{Análise dos recursos de suporte à PE}

Após a análise do processo de implementação das práticas de PE na empresa, foi possível identificar os recursos mais importantes para a implementação das práticas. A partir de um conjunto de 13 recursos identificados, foi utilizada uma matriz de relacionamentos, conforme descrito na seção 3 deste artigo, para avaliar o grau de influência de cada recurso na implementação das práticas. Essa matriz é apresentada na Figura 6.

Analisando a Figura 6, foi possível verificar que os recursos mais importantes para a implementação da PE foram respectivamente: gerentes e funcionários, cultura organizacional, valores da organização, equipamentos, materiais que são transformados pelo processo e máquinas.

O recursos de maior influência para a implementação de todas as práticas foram as pessoas da organização, totalizando 55 pontos. Durante as entrevistas foi destacada diversas vezes a importância fundamental deste recurso intangível e que sem as pessoas qualificadas que a empresa dispõe nada teria sido implementado. A cultura e os valores da empresa também foram considerados muito relevantes, sendo fundamentais a participação e o envolvimento da alta direção para a criação de um ambiente cultural favorável. 
Figura 5 - Sequência de implementação da PE

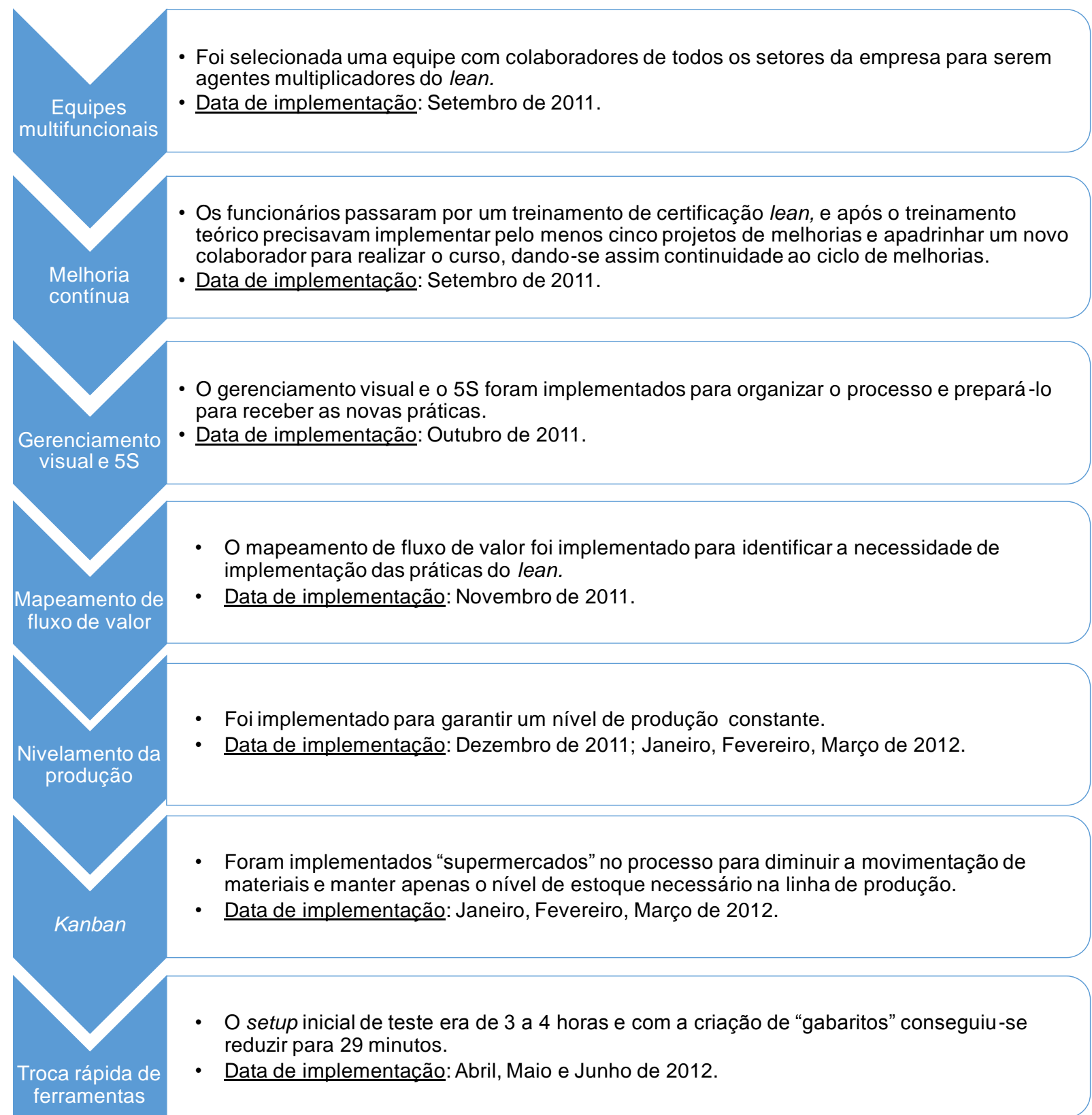

- Implementada apenas na linha de placas de circuito impresso devido à identificação de uma
grande incidência de quebra de máquina. Foi implementada apenas a manutenção
autônoma.

Fonte: Elaborada pelos autores

Com uma pontuação um pouco menor, 30, 34 e 32, respectivamente para máquinas, equipamentos e materiais transformados, esses recursos também foram considerados importantes, pois a implementação bem sucedida da PE depende de um profundo conhecimento do processo, assim como o que está sendo processado.

Revista Produção Online, Florianópolis, SC, v. 16, n. 4, p. 1309-1328, out./dez. 2016. 
A relação com o Governo teve influência no nivelamento de produção, pois a empresa precisa da liberação da matéria-prima pela SUFRAMA (Superintendência da Zona Franca de Manaus). Esse lead time, muitas vezes longo, pode prejudicar no nivelamento da produção, pois se pode conseguir seu nivelamento internamente, mas a matéria-prima pode demorar para ser entregue e liberada ao processo.

Figura 6 - Relacionamentos de práticas vs. recursos

\begin{tabular}{|c|c|c|c|c|c|c|c|c|c|c|c|c|c|}
\hline & & & & & & $\mathbf{R e}$ & urso & & & & & & \\
\hline Práticas & 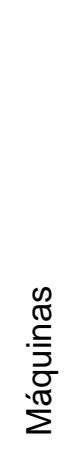 & 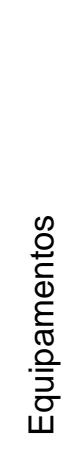 & 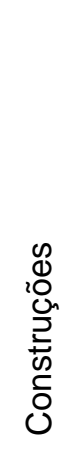 & 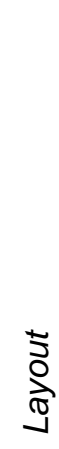 & 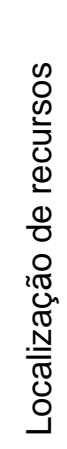 & 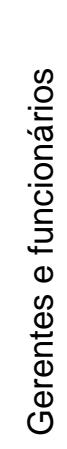 & 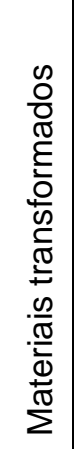 & 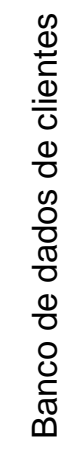 & 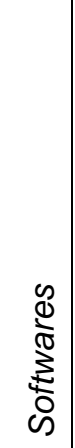 & 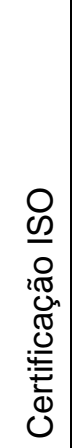 & 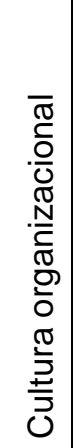 & 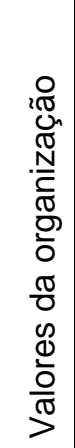 & 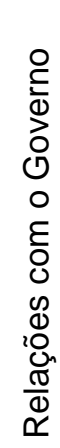 \\
\hline Equipes multifuncionais & & 4 & & & & 5 & 5 & & & & 5 & 5 & \\
\hline Gestão da qualidade no processo & & & & & & 5 & & & & 5 & 5 & 5 & \\
\hline Gerenciamento visual & & 3 & & 4 & & 5 & 5 & & & 5 & 5 & 5 & \\
\hline Produção puxada, JIT e Kanban & & & & 4 & 5 & 5 & 5 & 5 & & & 5 & 5 & \\
\hline Células de manufatura & 5 & 5 & & & 5 & 5 & & & & & 5 & 5 & \\
\hline Manutenção produtiva total (TPM) & 5 & 5 & & & & 5 & & & & & 5 & 5 & \\
\hline Mapeamento do fluxo de valor & 3 & & & & & 5 & 4 & & & & 5 & 5 & \\
\hline Melhoria contínua (Kaizen) & 4 & 4 & & & & 5 & & & 5 & & 5 & 5 & \\
\hline $\begin{array}{l}\text { Nivelamento da produção } \\
\text { (Heijunka) }\end{array}$ & 3 & 3 & & & 1 & 5 & 5 & & & & 5 & 5 & 5 \\
\hline Operações padronizadas & 5 & 5 & & & & 5 & 5 & & & & 5 & 5 & \\
\hline Troca rápida de ferramentas & 5 & 5 & 3 & & 5 & 5 & 3 & 5 & 5 & & 5 & 5 & \\
\hline Total & 30 & 34 & 3 & 8 & 16 & 55 & 32 & 10 & 10 & 10 & 55 & 55 & 5 \\
\hline
\end{tabular}

Fonte: Elaborada pelos autores

Os recursos mais importantes para a implementação, destacados nas áreas sombreadas da matriz de relacionamentos (Figura 6), foram denominados como recursos-chave da produção enxuta na empresa analisada. Esses recursos-chave foram escolhidos para a avaliação do valor, da sustentabilidade e da versatilidade. Devido à similaridade e para conferir maior praticidade na avaliação, os recursos "cultura organizacional" e "valores da organização" foram agrupados em uma única categoria de análise. O mesmo procedimento foi adotado para os recursos "máquinas" e "equipamentos". As planilhas relativas a essa avaliação são apresentadas nas Figuras 7, 8 e 9. 
Figura 7 - Avaliação do valor dos recursos-chave

\begin{tabular}{|c|c|c|c|c|c|}
\hline \multirow{2}{*}{$\begin{array}{l}\text { AVALIAÇÃO DO VALOR DOS } \\
\text { RECURSOS }\end{array}$} & \multicolumn{5}{|c|}{ PONTUAÇÃO } \\
\hline & 1 & 2 & 3 & 4 & 5 \\
\hline $\begin{array}{l}\text { Qual é o seu efeito sobre a } \\
\text { lucratividade da organização? }\end{array}$ & $\begin{array}{l}\text { Altamente } \\
\text { negativo }\end{array}$ & $\begin{array}{l}\text { Impacto } \\
\text { negativo } \\
\text { (MT) }\end{array}$ & Impacto nulo & $\begin{array}{l}\text { Impacto positivo } \\
\text { (GF) (ME) }\end{array}$ & $\begin{array}{l}\text { Altamente } \\
\text { positivo } \\
\text { (CV) }\end{array}$ \\
\hline $\begin{array}{l}\text { Qual é o seu efeito sobre a } \\
\text { habilidade da organização de } \\
\text { neutralizar ou minimizar as } \\
\text { ameaças do ambiente } \\
\text { competitivo? }\end{array}$ & $\begin{array}{l}\text { Altamente } \\
\text { negativo }\end{array}$ & $\begin{array}{l}\text { Impacto } \\
\text { negativo } \\
\text { (MT) }\end{array}$ & $\begin{array}{l}\text { Impacto nulo } \\
\text { (ME) }\end{array}$ & $\begin{array}{l}\text { Impacto positivo } \\
\text { (CV) }\end{array}$ & $\begin{array}{l}\text { Altamente } \\
\text { positivo } \\
\text { (GF) }\end{array}$ \\
\hline $\begin{array}{l}\text { Qual é a sua influência para } \\
\text { ajudar a empresa a explorar as } \\
\text { oportunidades de mercado? }\end{array}$ & $\begin{array}{l}\text { Altamente } \\
\text { negativo }\end{array}$ & $\begin{array}{l}\text { Impacto } \\
\text { negativo }\end{array}$ & $\begin{array}{l}\text { Impacto nulo } \\
\text { (GF) (ME) (MT) }\end{array}$ & Impacto positivo & $\begin{array}{l}\text { Altamente } \\
\text { positivo } \\
\text { (CV) }\end{array}$ \\
\hline $\begin{array}{l}\text { Quantos concorrentes já } \\
\text { possuem o mesmo recurso? }\end{array}$ & Todos & $\begin{array}{l}\text { A maioria } \\
\text { (MT) }\end{array}$ & Metade & $\begin{array}{l}\text { Alguns } \\
\text { (GF) (ME) }\end{array}$ & $\begin{array}{l}\text { Nenhum } \\
\text { (CV) }\end{array}$ \\
\hline $\begin{array}{l}\text { Comparado com a } \\
\text { concorrência, qual o nível de } \\
\text { desempenho desse recurso? }\end{array}$ & $\begin{array}{l}\text { Muito } \\
\text { abaixo da } \\
\text { média do } \\
\text { setor }\end{array}$ & $\begin{array}{l}\text { Abaixo da } \\
\text { média do } \\
\text { setor }\end{array}$ & Na média do setor & $\begin{array}{l}\text { No nível dos } \\
\text { melhores do } \\
\text { setor } \\
\text { (GF) (ME) (MT) }\end{array}$ & $\begin{array}{l}\text { Liderança } \\
\text { inquestionável } \\
\text { (CV) }\end{array}$ \\
\hline \multicolumn{6}{|c|}{$\begin{array}{l}\text { Legenda: } \\
\text { (CV) Cultura organizacional e valores; (GF) Gerentes e funcionários; (ME) Máquinas e equipamentos; (MT) Materiais } \\
\text { transformados. }\end{array}$} \\
\hline
\end{tabular}

Fonte: Pesquisa de campo

Figura 8 - Avaliação da sustentabilidade dos recursos-chave

\begin{tabular}{|c|c|c|c|c|c|}
\hline \multirow{2}{*}{$\begin{array}{c}\text { AVALIAÇÃO DA } \\
\text { SUSTENTABILIDADE DOS } \\
\text { RECURSOS }\end{array}$} & \multicolumn{5}{|c|}{ PONTUAÇÃO } \\
\hline & 1 & 2 & 3 & 4 & 5 \\
\hline $\begin{array}{l}\text { Com que facilidade os } \\
\text { concorrentes podem adquirir } \\
\text { este recurso? }\end{array}$ & Muito facilmente & $\begin{array}{l}\text { Com certa } \\
\text { facilidade } \\
\text { (ME) (MT) }\end{array}$ & $\begin{array}{l}\text { Com certa } \\
\text { dificuldade } \\
\text { (GF) }\end{array}$ & $\begin{array}{l}\text { Dificilmente } \\
\text { (CV) }\end{array}$ & $\begin{array}{l}\text { O recurso é } \\
\text { único }\end{array}$ \\
\hline $\begin{array}{l}\text { Quanto tempo demoraria para } \\
\text { um concorrente imitar este } \\
\text { recurso? }\end{array}$ & $\begin{array}{l}<1 \text { mês } \\
\text { (ME) (MT) }\end{array}$ & $1-6$ meses & 6-24 meses & $\begin{array}{l}2-5 \text { anos } \\
\text { (GF) }\end{array}$ & $\begin{array}{c}>5 \text { anos } \\
\text { (CV) }\end{array}$ \\
\hline $\begin{array}{l}\text { O recurso foi adquirido ou } \\
\text { desenvolvido por meio de } \\
\text { relacionamentos interpessoais e } \\
\text { confiança? }\end{array}$ & $\begin{array}{l}\text { De forma alguma } \\
\text { (ME) }\end{array}$ & $\begin{array}{l}\text { Dificilmente } \\
\text { (MT) }\end{array}$ & Parcialmente & $\begin{array}{l}\text { Em grande } \\
\text { parte }\end{array}$ & $\begin{array}{l}\text { Completamente } \\
\text { (CV) (GF) }\end{array}$ \\
\hline $\begin{array}{l}\text { O recurso foi adquirido ou } \\
\text { desenvolvido por meio do } \\
\text { aprendizado organizacional? }\end{array}$ & De forma alguma & $\begin{array}{l}\text { Dificilmente } \\
\text { (MT) }\end{array}$ & $\begin{array}{l}\text { Parcialmente } \\
\text { (ME) }\end{array}$ & $\begin{array}{l}\text { Em grande } \\
\text { parte } \\
\text { (GF) }\end{array}$ & $\begin{array}{c}\text { Completamente } \\
\text { (CV) }\end{array}$ \\
\hline $\begin{array}{l}\text { O recurso pode ser substituído } \\
\text { por outro recurso para a } \\
\text { obtenção de um resultado } \\
\text { similar? }\end{array}$ & $\begin{array}{l}\text { Completamente } \\
\text { (ME) }\end{array}$ & $\begin{array}{l}\text { Em grande } \\
\text { parte }\end{array}$ & $\begin{array}{l}\text { Parcialmente } \\
\text { (MT) }\end{array}$ & $\begin{array}{l}\text { Dificilmente } \\
\quad \text { (GF) }\end{array}$ & $\begin{array}{l}\text { De forma } \\
\text { alguma } \\
\text { (CV) }\end{array}$ \\
\hline \multicolumn{6}{|c|}{$\begin{array}{l}\text { Legenda: } \\
\text { (CV) Cultura organizacional e valores; (GF) Gerentes e funcionários; (ME) Máquinas e equipamentos; (MT) Materiais } \\
\text { transformados. }\end{array}$} \\
\hline
\end{tabular}

Fonte: Pesquisa de campo 
Figura 9 - Avaliação da versatilidade dos recursos-chave

\begin{tabular}{|c|c|c|c|c|c|}
\hline \multirow{2}{*}{$\begin{array}{l}\text { AVALIAÇÃO DA } \\
\text { VERSATILIDADE DOS } \\
\text { RECURSOS }\end{array}$} & \multicolumn{5}{|c|}{ PONTUAÇÃO } \\
\hline & 1 & 2 & 3 & 4 & 5 \\
\hline $\begin{array}{l}\text { O recurso pode ser } \\
\text { transferido para outros } \\
\text { setores ou unidades na } \\
\text { empresa? }\end{array}$ & Impossível & $\begin{array}{l}\text { Com } \\
\text { dificuldade } \\
\text { (MT) }\end{array}$ & $\begin{array}{l}\text { Com algum } \\
\text { esforço } \\
\text { (CV) (GF) }\end{array}$ & $\begin{array}{l}\text { Facilmente } \\
\text { (ME) }\end{array}$ & Muito facilmente \\
\hline $\begin{array}{l}\text { Este recurso depende de } \\
\text { recursos e/ou processos } \\
\text { complementares para ser } \\
\text { transferido? }\end{array}$ & Completamente & $\begin{array}{l}\text { Depende } \\
\text { bastante } \\
\text { (MT) }\end{array}$ & $\begin{array}{l}\text { Parcialmente } \\
\text { (CV) (GF) }\end{array}$ & $\begin{array}{l}\text { Depende pouco } \\
\text { (ME) }\end{array}$ & Independente \\
\hline $\begin{array}{l}\text { Este recurso está vinculado } \\
\text { a alguma região } \\
\text { geográfica? }\end{array}$ & $\begin{array}{l}\text { Vínculo total } \\
\text { (CV) }\end{array}$ & $\begin{array}{l}\text { Vínculo forte } \\
\text { (MT) }\end{array}$ & Vínculo parcial & $\begin{array}{l}\text { Vínculo fraco } \\
\text { (ME) }\end{array}$ & $\begin{array}{c}\text { Nenhum vínculo } \\
\text { (GF) }\end{array}$ \\
\hline $\begin{array}{l}\text { Quanto tempo demoraria } \\
\text { para reproduzir este recurso } \\
\text { em outra parte da } \\
\text { organização? }\end{array}$ & $>5$ anos & $2-5$ anos & $\begin{array}{l}\text { 6-24 meses } \\
\text { (CV) (GF) (ME) }\end{array}$ & $\begin{array}{l}\text { 1-6 meses } \\
\text { (MT) }\end{array}$ & $<1$ mês \\
\hline $\begin{array}{l}\text { A organização tem um } \\
\text { conhecimento explícito dos } \\
\text { fatores necessários para } \\
\text { reproduzir este recurso? }\end{array}$ & $\begin{array}{l}\text { De forma } \\
\text { alguma }\end{array}$ & Muito pouco & Parcialmente & $\begin{array}{l}\text { Em grande } \\
\text { parte } \\
\text { (CV) (GF) (ME) } \\
\text { (MT) }\end{array}$ & Completamente \\
\hline \multicolumn{6}{|c|}{$\begin{array}{l}\text { Legenda: } \\
\text { (CV) Cultura organizacional e valores; (GF) Gerentes e funcionários; (ME) Máquinas e equipamentos; (MT) Materiais } \\
\text { transformados. }\end{array}$} \\
\hline
\end{tabular}

Fonte: Pesquisa de campo

De acordo com os resultados demonstrados nas planilhas de avaliação, foi possível, a partir da pontuação total, classificar os recursos-chave em relação aos critérios de valor, sustentabilidade e versatilidade (Quadro 3).

Quadro 3 - Resumo da avaliação dos recursos-chave

\begin{tabular}{|l|c|c|c|c|c|c|}
\cline { 2 - 8 } \multicolumn{1}{c|}{} & \multicolumn{6}{c|}{ Pontuação total e Classificação } \\
\hline Recursos & \multicolumn{3}{|c|}{ Valor } & \multicolumn{2}{c|}{ Sustentabilidade } & \multicolumn{2}{c|}{ Versatilidade } \\
\hline (CV) Cultura organizacional e valores & 24 & Muito alto & 24 & Muito alta & 14 & Média \\
\hline (GF) Gerentes e funcionários & 20 & Alto & 20 & Alta & 18 & Alta \\
\hline (ME) Máquinas e equipamentos & 18 & Alto & 8 & Muito baixa & 19 & Alta \\
\hline (MT) Materiais transformados & 13 & Médio & 10 & Baixa & 14 & Média \\
\hline
\end{tabular}

Fonte: Elaborado pelos autores

Foi possível observar que a cultura organizacional e os valores assumem um caráter de recurso estratégico para a produção enxuta na empresa. Identificou-se que a fábrica já desenvolveu um pensamento enxuto, enquanto os concorrentes ainda estão longe deste ideal. $O$ fato de a fábrica pertencer a uma empresa multinacional americana também favoreceu o desenvolvimento da cultura enxuta, pois esta já estava presente na sede, enquanto os concorrentes, de origem chinesa, não dispunham dessa vantagem. Entretanto, observou-se que a versatilidade do recurso "cultura e valores" ainda pode ser melhorada, uma vez que ainda se constata uma dificuldade inerente de se transferir a cultura enxuta para outras unidades. 
A importância dos recursos humanos foi mais uma vez destacada pelo alto desempenho na avaliação do recurso "gerentes e funcionários". A alta direção da empresa tem uma consciência clara da contribuição das pessoas para o sucesso da produção enxuta e de quaisquer outros programas de melhoria. Por isso, é rigorosa no processo de seleção de funcionários, investe uma quantia significativa em treinamento e estimula a proatividade de seu pessoal para a resolução de problemas. Juntamente com a cultura enxuta que foi desenvolvida, a empresa atribui o sucesso na implementação ao desempenho de seus funcionários.

O recurso "máquinas e equipamentos", embora importante para o sistema de produção enxuta, demonstra uma sustentabilidade muito baixa, especialmente pela facilidade que existe para os concorrentes imitarem. No entanto, a empresa já teve a experiência de desenvolver projetos e adaptações empregando know-how e tecnologia próprios. Isso pode sinalizar desenvolvimentos futuros para aumentar a sustentabilidade desse recurso.

O materiais transformados também demonstram uma certa fragilidade como recursos essenciais para a produção enxuta. A maior parte dos componentes são importados e estão disponíveis de igual maneira para os concorrentes. Foi constatado que os componentes em si não garantem o sucesso da produção enxuta, mas sim, a maneira que eles são gerenciados.

A identificação e a avaliação dos recursos-chave proporcionou um olhar diferente ao processo de implementação da PE. Com base na pesquisa realizada, e apoiando-se na literatura da área, foi possível extrair algumas diretrizes para o processo de implementação, válidas para a empresa pesquisada, mas com potencial utilidade para outras situações:

- É importante iniciar com um foco em treinamento e integração das práticas da produção enxuta à cultura e aos valores da empresa.

- É fundamental ter apoio da alta direção, garantindo a participação de todos os colaboradores da empresa no processo de implementação.

- Após o treinamento e a integração dos colaboradores, devem-se verificar as características particulares do processo, além da necessidade de máquinas e materiais para a implementação de cada prática, identificando o que já se encontra disponível e o que necessitará de recursos financeiros para serem adquiridos.

- Após a alocação dos recursos financeiros para a implementação, a empresa deve focar na melhoria do processo produtivo, definindo um layout adequado e eliminando atividades que não agregam valor.

Não menos importante, quando a empresa tem a certificação ISO e já participou previamente de programas de qualidade, aumenta-se a facilidade em conseguir o comprometimento das pessoas para incorporar as práticas da produção enxuta à cultura da empresa.

O estudo de caso realizado comprovou que o desenvolvimento de uma cultura enxuta e a valorização da contribuição das pessoas são fundamentais para a 
implementação e a manutenção do sistema de produção enxuta. Especialmente no caso estudado, esses foram os recursos mais importantes para a implementação.

\section{CONSIDERAÇÕES FINAIS}

Este artigo identificou um conjunto de práticas de produção enxuta adotadas por uma unidade fabril de uma empresa de manufatura eletrônica no Estado do Amazonas, assim como uma lista de recursos que influenciaram na implementação dessas práticas. Os resultados confirmaram que há relação entre as práticas da produção enxuta e os recursos disponíveis na empresa, que exerceram um papel fundamental para o sucesso da implementação.

Os recursos intangíveis foram mais significativos para a implementação das práticas da produção enxuta na empresa estudada, notadamente: cultura organizacional, valores da empresa e funcionários. Além disso, percebeu-se que foi de grande importância, antes de iniciar a implementação de qualquer prática, realizar treinamentos e preparar a empresa previamente com práticas de $5 \mathrm{~S}$ e gerenciamento visual, tornando o ambiente fértil para a PE.

Este trabalho trouxe contribuições para a literatura da área e para empresas que desejam implementar a produção enxuta. Para a empresa, o desenvolvimento do estudo de caso permitiu identificar os principais recursos utilizados no processo de implementação da produção enxuta, assim como a importância destes. Dessa forma, a empresa poderá desenvolver mecanismos de proteção destes recursos, pois estes estão contribuindo para a implementação da PE e, em uma perspectiva de longo prazo, para a vantagem competitiva da empresa. Por outro lado, foi possível identificar quais recursos são mais representativos para cada prática enxuta, o que ajuda a melhorar a decisão sobre quais recursos investir de acordo com as prioridades de implementação.

Ao identificar e avaliar os recursos de suporte à produção enxuta na empresa, a pesquisa corroborou com os estudos que identificam fatores críticos de sucesso e barreiras para a implementação da PE. Porém, essa pesquisa se diferencia dos demais estudos por trazer uma perspectiva estratégica ao tema, por meio da visão baseada em recursos.

Para dar continuidade a este trabalho, recomenda-se que sejam feitas pesquisas para verificar se o roteiro de implementação utilizado pela empresa é coerente com o que se propõe na literatura e se de fato existe a necessidade de estabelecer um sequência de implementação que dá destaque ao desenvolvimento de recursos de suporte. Além disso, sugere-se identificar, por meio de um survey, se os recursos considerados importantes para implementação da PE podem ser generalizados em outras situações de implementação. Destaca-se aqui o papel essencial da cultura enxuta e dos recursos humanos como fatores críticos de sucesso para a $\mathrm{PE}$, o que indica que a pesquisa neste tema continua fértil e promissora. 


\section{REFERÊNCIAS}

BARNEY, J. B.; HESTERLY, W. S. Administração estratégica e vantagem competitiva: casos brasileiros. São Paulo: Pearson, 2007.

BHASIN, S.; BURCHER, P. Lean viewed as a philosophy. Journal of Manufacturing Technology Management, v. 17, n. 1, p. 56-72, 2006.

http://dx.doi.org/10.1108/17410380610639506

FLEURY, A. C. C; FLEURY, M. T. L. Estratégias competitivas e competências essenciais: perspectivas para a internacionalização da indústria no Brasil. Gestão \& Produção, v. 10, n. 2, p. 129-144, 2003. http://dx.doi.org/10.1590/S0104-530X2003000200002

FORRESTER, P. L. et al. Lean production, market share and value creation in the agricultural machinery sector in Brazil. Journal of Manufacturing Technology Management, v. 21, n. 7, p. 853-871, 2010. http://dx.doi.org/10.1108/17410381011077955

GIBBONS, P. M. et al. The development of a lean resource mapping framework: introducing an 8th waste. International Journal of Lean Six Sigma, v. 3, n. 1, p. 4-27, 2012. http://dx.doi.org/10.1108/20401461211223704

GOHR, C. F.; SILVA, Y. L. T. V. Gerenciando o relacionamento entre recursos estratégicos e prioridades competitivas segundo a visão baseada em recursos. Revista Produção Online, v. 15, n. 2, p. 734-757, 2015. http://dx.doi.org/10.14488/1676-1901.v15i2.1939

JAYAMAHA, N. P. et al. Testing a theoretical model underlying the 'Toyota Way'- an empirical study involving a large global sample of Toyota facilities. International Journal of Production Research, v. 52, n. 14, p. 4332-4350, 2014.

http://dx.doi.org/10.1080/00207543.2014.883467

KHANCHANAPONG, T. et al. The unique and complementary effects of manufacturing technologies and lean practices on manufacturing operational performance. International Journal of Production Economics, v. 153, p. 191-203, 2014.

http://dx.doi.org/10.1016/j.ijpe.2014.02.021

KRAAIJENBRINK, J.; SPENDER, J.-C.; GROEN, A. J. The resource-based view: a review and assessment of its critiques. Journal of Management, v. 36, n. 1, p. 349-372, 2010. http://dx.doi.org/10.1177/0149206309350775

LEWIS, M. A. Lean production and sustainable competitive advantage. International Journal of Operations \& Production Management, v. 20, n. 8, p. 959-978, 2000. http://dx.doi.org/10.1108/01443570010332971

LIKER, J. K. O modelo Toyota: 14 princípios de gestão do maior fabricante do mundo. 2 ed. Porto Alegre: Bookman, 2005.

MILLS, J. et al. Competing through competences. Cambridge, UK: Cambridge University Press, 2002.

MONDEN, Y. Sistema Toyota de produção: uma abordagem integrada ao just-in-time. 4.ed. Porto Alegre: Bookman, 2015. 
OHNO, T. O sistema Toyota de produção: além da produção em larga escala. Porto Alegre: Bookman, 1997.

PARRY, G.; MILLS, J.; TURNER, C. Lean competence: integration of theories in operations management practice. Supply Chain Management: An International Journal, v. 15, n. 3, p. 216-226, 2010. http://dx.doi.org/10.1108/13598541011039974

SANTOS, L. C. et al. Como dar suporte às estratégias de empresas hoteleiras? Uma análise segundo a visão baseada em recursos. Production, v. 25, n. 2, p. 403-415, 2015. http://dx.doi.org/10.1590/0103-6513.036612

SAURIN, T. A.; FERREIRA, C. F. Avaliação qualitativa da implantação de práticas da produção enxuta: estudo de caso em uma fábrica de máquinas agrícolas. Gestão \& Produção, v. 15, n. 3, p. 449-462, 2008. http://dx.doi.org/10.1590/S0104-

530X2008000300003

SHINGO, S. O sistema Toyota de produção: do ponto de vista da engenharia de produção. 2 ed. Porto Alegre: Bookman, 1996.

SILVA, A. T. C. A contribuição dos recursos estratégicos para a implantação da produção enxuta e para a vantagem competitiva em uma organização calçadista do Estado da Paraíba. 2014. 132 f. Dissertação (Mestrado) - Programa de Pós-Graduação em Engenharia de Produção, Universidade Federal da Paraíba, João Pessoa, 2014.

TAYLOR, A.; TAYLOR, M.; MCSWEENEY, A. Towards greater understanding of success and survival of lean systems. International Journal of Production Research, v. 51, n. 22, p. 6607-6630, 2013. http://dx.doi.org/10.1080/00207543.2013.825382

TORTORELLA, G. L. et al. Dimensões do aprendizado organizacional: variáveis contextuais em empresas em implementação enxuta. Revista Produção Online, v. 14, n. 3, p. 10771103, 2014. http://dx.doi.org/10.14488/1676-1901.v14i3.1669

VEIGA, G. L. Uma discussão sobre o papel estratégico do modelo de produção enxuta. 2009. 212 f. Dissertação (Mestrado) - Programa de Pós-Graduação em Engenharia de Produção e Sistemas, Pontifícia Universidade Católica do Paraná, Curitiba, 2009.

WOMACK, J. P.; JONES, D. T. Lean thinking: banish waste and create wealth in your corporation. New York, NY: Free Press, 2003.

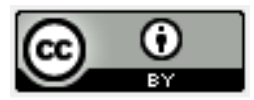

Artigo recebido em 06/02/2016 e aceito para publicação em 10/03/2016

DOI:http://dx.doi.org/ 10.14488/1676-1901.v16i4.2343 